\title{
Microbiological Degradation of Bile Acids
}

\section{THE CONJUGATION OF A CERTAIN CHOLIC ACID METABOLITE WITH AMINO ACIDS IN CORYNEBACTERIUM EQUI}

\author{
By SHOHEI HAYAKAWA, TAKASHI FUJIWARA and HARUKO KAKO* \\ Shionogi Research Laboratory, Shionogi and Co. Ltd., Fukushima-ku, Osaka, 553 Japan
}

\author{
(Received 22 March 1976)
}

\begin{abstract}
1. (4R)-4-[4 $\alpha$-(2-Carboxyethyl)-3a $\alpha$-hexahydro-7a $\beta$-methyl-5-oxoindan- $1 \beta$-yl]valeric acid (II) could not be utilized by Arthrobacter simplex, even though the acid was one of the metabolites formed from cholic acid (I) by this organism. Therefore the further degradation of the acid (II) by Corynebacterium equi was investigated to identify the intermediates involved in the cholic acid degradation. 2 . The organism, cultured in a medium containing the acid (II) as the sole source of carbon, produced unexpected metabolites, the conjugates of this original acid (II) with amino acids or their derivatives, although the yield was very low. These new metabolites were isolated and identified by chemical synthesis as the $N^{\alpha}-\{(4 R)-4-[4 \alpha-(2$-carboxyethyl)-3a $\alpha$-hexahydro-7a $\beta$-methyl-5-oxoindan-1 $\beta$-yl]valeryl\} derivatives of L-alanine, glutamic acid, $O$-acetylhomoserine and glutamine, i.e. compounds (III $a$ ), (III $b$ ), (III $c$ ) and (III $d$ ) respectively. 3 . The possibility that the bacterial synthetic reaction observed in the acid (II) metabolism with C. equi is analogous to peptide conjugation known in both animals and higher plants is discussed. A possible mechanism for this bacterial conjugation is also considered.
\end{abstract}

Our continued interest in the intermediates and reaction sequence involved in the degradation of $3 \alpha, 7 \alpha, 12 \alpha$-trihydroxy-5 $\beta$-cholan-24-oic acid (cholic acid) (I) by micro-organisms has prompted us to search for further degradation products of $(4 R)-4$ [4 $\alpha$-(2-carboxyethyl)-3a $\alpha$-hexahydro-7a $\beta$-methyl-5oxoindan-1 $\beta$-yl]valeric acid (II), which was one of the degradation products formed from cholic acid (I) by Arthrobacter simplex (Hayakawa et al., 1969) (Scheme 1). As described in a previous paper, however, the oxodicarboxylic acid (II) could not be utilized by this organism (Hayakawa et al., 1976a). As one of the approaches to this problem, therefore, we made a search for other micro-organisms that are able to utilize the acid (II), and found that Corynebacterium equi was able to achieve this degradation (cf. Hayakawa et al., 1976b).

The present paper describes the isolation and identification of new metabolites formed from the acid (II) by C. equi; a preliminary note of this work has already appeared (Hayakawa et al., 1968).

\section{Results}

Isolation of the metabolites and their structure assignments

No growth of $A$. simplex occurred in both a medium containing the oxodicarboxylic acid (II)

* Née Tsuchikawa.
$(1 \mathrm{~g} / \mathrm{l})$ as the sole source of carbon and the same medium supplemented with yeast extract $(0.5 \mathrm{~g} / \mathrm{l})$. C. equi was also unable to grow in the former but grew well in the latter, and it very rapidly degraded the acid (II) without apparent accumulation of metabolites. However, C. equi pre-cultured in the latter was able to grow well even in the former, and rapidly degrade the acid (II), so that it was difficult to monitor the course of the degradation of the acid (II) and of the formation of its metabolites by t.l.c. It was possible to accomplish the monitoring by increasing the concentration of the acid (II) in the former up to $3 \mathrm{~g} / \mathrm{l}$. Further, compared with this case, $C$. equi, precultured in a medium containing yeast extract $(0.5 \mathrm{~g} / \mathrm{l})$ and $(4 R)-4-[3 \mathrm{a} \alpha$-hexahydro- $5 \beta$-hydroxy- $4 \alpha-$ (3-hydroxypropyl) - 7a $\beta$-methylindan $-1 \beta$-yl]valeric acid (VI) $(1 \mathrm{~g} / 1)$ instead of the acid (II) as carbon sources, degraded both the acid (II) and its metabolites more slowly in this $0.3 \%$ medium and afforded a better yield of the metabolites. However, if the incubation is continued until the acid (II) is completely consumed, once-formed metabolites were further degraded even under such conditions. Then the incubation was stopped when a small amount of the unaltered acid (II) was still present in the incubation mixture, and the mixture was immediately used for the isolation of metabolites.

(a) L-Alanine conjugate. This was isolated as crystals, its elementary analysis was consistent with 


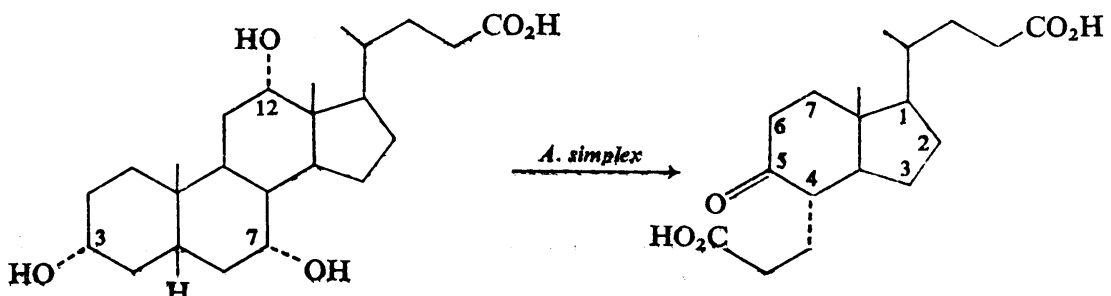

(I)

(II)<smiles>[R]C(NC(=O)CCC(C)C1CCC2[C@H](CCC(=O)O)C(=O)CC[C@]12C)C(=O)O</smiles>

$$
\begin{aligned}
& \text { (III) }(a) \mathrm{R}=\mathrm{Me} \text {; } \\
& \text { (b) } \mathrm{R}=\left[\mathrm{CH}_{2}\right]_{2}-\mathrm{CO}_{2} \mathrm{H} \text {; } \\
& \text { (c) } \mathrm{R}=\mathrm{CH}_{2}-\mathrm{CH}_{2} \mathrm{OAc} \text {; } \\
& \text { (d) } \mathrm{R}=\left[\mathrm{CH}_{2}\right]_{2}-\mathrm{CONH}_{2}
\end{aligned}
$$

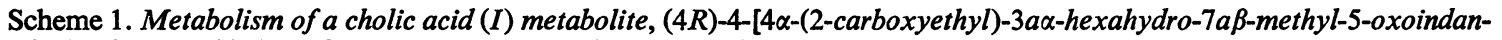
$1 \beta$-yl]valeric acid $(I I)$, to form its conjugates with amino acids.

$\mathrm{C}_{21} \mathrm{H}_{33} \mathrm{NO}_{6}$ and non-aqueous titration gave a neutralization equivalent of 380 as dicarboxylic acids. The i.r. spectrum showed the presence of both amide and carboxyl groups at 3460, 1617 and 1551 and approx. 3200, approx. 2500,1740 and $1700 \mathrm{~cm}^{-1}$ respectively. On being heated with $6 \mathrm{M}-\mathrm{HCl}$ to hydrolyse the amide bond, the metabolite yielded the acid (II) and a ninhydrin-positive substance. The latter corresponded to alanine in the amino acid analyser. It was then converted into the corresponding $\mathrm{N}$-2,4-dinitrophenyl derivative and isolated as crystals by the method of Sanger (1945). Identity with an authentic sample of $N$-2,4-dinitrophenyl-L-alanine was established by direct comparison. From these data, the structure of this metabolite was assigned as either $N$-\{(4R)-4-[4 $\alpha$-(2-carboxyethyl)-3a $\alpha$-hexa hydro - $7 \mathrm{a} \beta$ - methyl -5 - oxoindan $-1 \beta$-yl]valeryl $\}-\mathrm{L}$ alanine (III $a)$ or its position isomer, $N-(3-\{1 \beta-[(1 R)-3-$ carboxy - 1 - methylpropyl] - 3a $\alpha$ - hexahydro - 7a $\beta$ methyl - 5 - oxoindan - $4 \alpha$ - yl propionyl) - $\mathrm{L}$ - alanine. Support for this assignment was further provided by the i.r. and n.m.r. spectra of the corresponding dimethyl ester (see under 'Isolation of the metabolites' in the Experimental section).

(b) L-Glutamic acid conjugate. This was isolated as the crystalline monosodium salt, and the i.r. spectrum indicated the presence of an amide bond. On hydrolysis with $6 \mathrm{M}-\mathrm{HCl}$, it afforded the acid (II) and a substance that corresponded to glutamic acid in the amino acid analyser. Thus it was concluded that this metabolite is the monosodium salt of either $N-\{(4 R)-4-[4 \alpha-(2$-carboxyethyl)-3a $\alpha$-hexahyd ro-7a $\beta$ methyl-5-oxoindan-1 $\beta$-yl]valeryl $\}$ glutamic acid (IIIb) or its position isomer with respect to the glutamic acid moiety, although the elementary analysis gave no satisfactory values. Further, the evidence obtained from the i.r. and n.m.r. spectra of the corresponding trimethyl ester was consistent with this assignment (see under 'Isolation of the metabolites' in the Experimental section).

(c) $O$-Acetyl-L-homoserine conjugate. This was isolated as a mixture of two components, which behaved as one spot on t.l.c., but, after esterification, moved as two spots. However, another sample, which moved as a practically single spot on t.l.c. in both the free acid and methyl ester forms, was obtained from another run as amorphous materials. Both the samples, on hydrolysis with $6 \mathrm{M}-\mathrm{HCl}$, yielded the same products, namely the acid (II) and two ninhydrin-positive substances. The latter were 
detected by the amino acid analyser, but their nature is unknown, except that the major component was a basic substance. Then the methyl ester of the latter sample was subjected to i.r. and n.m.r. spectrometries: both the spectra showed bands at 3430,1737 , 1703,1676 and $1502 \mathrm{~cm}^{-1}$ and signals at $\delta$ approx. 0.93 (superimposable doublet; 3H), 0.99 (singlet; $3 \mathrm{H}$ ), 2.03 (singlet; $3 \mathrm{H}$ ), 3.65 (singlet; $3 \mathrm{H}), 3.76$ (singlet, $3 \mathrm{H}$ ); 4.13 (triplet; 2H), 4.67 (multiplet; $1 \mathrm{H}$ ) and 6.11 (broad peak; 1H) p.p.m. respectively. A doublet at $\delta 0.93(3 \mathrm{H})$ and a singlet at $\delta 0.99(3 \mathrm{H})$ p.p.m. in the n.m.r. spectrum could be assigned to protons of the secondary and tertiary methyl groups in the acid (II) moiety respectively. The presence of one $O$-acetyl and two methoxycarbonyl (ester methyl) groups was indicated by the respective three sharp singlets at $\delta 2.03(3 \mathrm{H}), 3.65(3 \mathrm{H})$ and $3.76(3 \mathrm{H})$ p.p.m. in the n.m.r. spectrum and by a strong absorption at $1737 \mathrm{~cm}^{-1}$ in the i.r. spectrum. By comparing the n.m.r. spectrum with those of the respective methyl esters of the above L-alanine and glutamic acid conjugates, a multiplet at $\delta 4.67(1 \mathrm{H})$ and a broad peak at $\delta 6.11$ (1H) p.p.m. in the n.m.r. spectrum could be assigned to protons of the methine and monoacylated amino groups in the ninhydrin-positive substance (probably an $\alpha$-amino acid) respectively. The presence of this mono-acylated amino group was further indicated by absorptions at 3430 (NH) and 1676 and $1502(\mathrm{CONH}) \mathrm{cm}^{-1}$ in the i.r. spectrum. A triplet at $\delta 4.13(2 \mathrm{H})$ p.p.m. in the n.m.r. spectrum could be assigned to two protons of an acetoxymethylene group attached to a particular methylene group in the $\alpha$-amino acid moiety; this was further supported by the presence of an $O$-acetyl group described above. An absorption at $1703 \mathrm{~cm}^{-1}$ in the i.r. spectrum was assigned as the carbonyl group in the acid (II) moiety. Accordingly it was concluded that the $\alpha$-amino acid moiety in this conjugate is $O$ acetylhomoserine.

Armstrong (1949) reported that homoserine was in equilibrium with its lactone form, 2-amino-4 hydroxybutyric acid lactone ( $\alpha$-amino- $\gamma$-butyrolactone); increasing amounts of the lactone are present in more strongly acidic solutions. It could therefore be conceivable that the major basic substance in the hydrolysate might be $\alpha$-amino- $\gamma$-butyrolactone and another minor component homoserine. This was further confirmed by direct comparison with authentic samples of these compounds in the amino acid analyser. Thus the structure of this metabolite was assigned as either $O$-acetyl- $N$ - $\{(4 R)-4$-[4 $\alpha$-(2-carboxyethyl)-3a $\alpha$-hexahydro-7a $\beta$-methyl-5-oxoindan $-1 \beta$ ylvaleryl\}homoserine (III $c$ ) or its position isomer with respect to the $\boldsymbol{O}$-acetylhomoserine moiety.

That the sample, which was isolated from the first run and consisted of two components, was a mixture of the respective conjugates of the acid (II) with $O$-acetylhomoserine and $\alpha$-amino- $\gamma$-butyrolactone was established by direct comparison with the synthetic samples of these conjugates.

(d) L-Glutamine conjugate. The fourth metabolite was isolated as an amorphous powder containing minute quantities of impurities. On hydrolysis with $6 \mathrm{M}-\mathrm{HCl}$, it produced the acid (II) and approximately equal amounts of glutamic acid and ammonia. Thus the structure of this metabolite was assigned as a primary mono-amide derivative of either one of the six carboxyl groups in the two possible structures of the above glutamic acid conjugate. The i.r. and n.m.r. spectra of the corresponding dimethyl ester, which was purified by preparative t.l.c., were fully consistent with this assignment (see under 'Isolation of the metabolites' in the Experimental section). However, it was unknown from these data whether the metabolite was the conjugate of the acid (II) with glutamine itself until its partial synthesis was achieved.

\section{Partial syntheses of the conjugates}

Which isomer of the respective two possible structures for the L-alanine, glutamic acid and $O$ acetylhomoserine conjugates was correct was ascertained by partial synthesis (Scheme 2).

L-Alanine conjugate (IIIa). We at first synthesized one of the two possible isomers of the L-alanine conjugate, the hexahydroindanylvaleryl-L-alanine (III $a$ ), since we have kept a convenient starting material, (4R) - 4- $(2,3,4,6,6 \mathrm{a} \beta, 7,8,9,9 \mathrm{a} \alpha, 9 \mathrm{~b} \beta$ - decahydro - $6 \mathrm{a} \beta$ methyl - 3 - oxo - $1 H$-cyclopenta[f]quinolin - $7 \beta$ - yl]valeric acid (IV) (Hayakawa et al., 1976b), in which the propionic acid side chain of the oxodicarboxylic acid (II) was already protected against a coupling reaction with amino acids as an enaminolactam form. The enaminolactam acid (IV) was converted into the corresponding L-alanine conjugate (V) by the usual coupling method of mixed carbonic-carboxylic anhydrides with amino acids, which had been applied for the partial syntheses of conjugated bile acids by Norman (1955). On partial hydrolysis with dilute $\mathrm{HCl}$ in dioxan, the conjugate $(\mathrm{V})$ afforded the hexahydroindanylvaleryl-L-alanine (III $a$ ). Fortunately, the synthetic sample was identical in all respects (t.l.c., m.p., mixed m.p., $[\alpha]_{\mathrm{D}}$ and i.r.) with the L-alanine conjugate isolated from growing cultures. The result also excluded another possible structure for this metabolite, the hexahydroindanylpropionylL-alanine.

The above synthetic method gave trouble in the isolation of the final product. It also appeared that this method would be unsatisfactory for the syntheses of the $\boldsymbol{O}$-acetylhomoserine and glutamine conjugates, which are labile to hot dilute $\mathrm{HCl}$. While our study was in progress, we came across a publication on the syntheses of $N$-acylamino acids using $N$-hydroxysuccinimide esters by Lapidot et al. (1967). The method was used for our synthetic work. Since 
<smiles>CCOC(=O)NCCCCC(C)C1CCC2C3CCC(=O)NC3=CCC12C</smiles>

(IV)<smiles>CC(NC(=O)CCC(C)C1CCC2C3CCC(=O)NC3=CCC12C)C(=O)O</smiles>

(V)<smiles>CCCCC(C)C1CCC2C(CCC(=O)O)C(O)CCC12C</smiles><smiles>[Y]C(C)Cl</smiles>
(III $a),($ III $b)$ or (III $d)$ $\uparrow \begin{aligned} & \text { L-Alanine, } \\ & \text { L-glutamic acid } \\ & \text { or L-glutamine }\end{aligned}$<smiles>CC(CCC(=O)O)C1CCC2C3CCCOC3CCC12C</smiles>

(VII)<smiles>CC(CCC(=O)ON1C(=O)CCC1=O)C1CCC2[C@@H](CCC(=O)O)C(=O)CCC12C</smiles>

(VIII)<smiles>CC(CCC(=O)NC1CCOC1=O)C1C(=O)OC(C)C1C(=O)O</smiles>

Scheme 2. Partial syntheses of the respective $N^{\alpha}-\{(4 R)-4-[4 \alpha-(2-c a r b o x y e t h y l)-3 a \alpha-h e x a h y d r o-7 a \beta-m e t h y l-5-o x o i n d a n-$ $1 \beta$-yl]valeryl derivatives of $\mathrm{L}$-alanine, L-glutamic acid, O-acetyl-L-homoserine and L-glutamine, (IIIa), (IIIb), (IIIc) and (IIId).

(4R)-4-[3a $\alpha$-hexahydro-5 $\beta$-hydroxy-4 $\alpha$-(3-hydroxypropyl) - 7a $\beta$ - methylindan - $1 \beta$-yl]valeric acid (VI) was easily available to us (Hayakawa et al., 1976a), the $5 \beta$-dihydroxy acid was converted into its $N$ hydroxysuccinimide ester (VII) and then oxidized with Jones reagent (Curtis $e t$ al., 1953) to yield the halfester (VIII) of the acid (II) with $N$-hydroxysuccinimide. The half-ester was coupled with $\mathrm{L}$-alanine to afford the corresponding L-alanine conjugate (III $a$ ).

L-Glutamic acid conjugate (IIIb). Exactly as described above for the L-alanine conjugate (III $a$ ),
L-glutamic acid was condensed with the half-ester (VIII) to afford the crystalline disodium salt of the corresponding L-glutamic acid conjugate (III $b$ ). The synthetic sample gave no satisfactory analytical values, but the behaviour on t.l.c. was identical with that of the glutamic acid conjugate obtained from growing cultures. Since the isolated sample had been obtained as its monosodium salt, both the i.r. spectra of these samples were not identical, of course, with each other. However, the corresponding trimethyl ester, prepared from the disodium salt, was identical 
in all respects (t.l.c., i.r. and n.m.r.) with the trimethyl ester of the isolated sample.

$O$-Acetyl-L-homoserine conjugate (IIIc). The crystalline disodium salt of L-homoserine conjugate (IX), prepared by coupling the half-ester (VIII) with L-homoserine, was treated by the $O$-acetylation method for hydroxyamino acids reported by Sakami \& Toennies (1942) and yielded a mixture of products, which mainly consisted of two components. After esterification, each component was isolated as methyl esters. The major one was identified as the methyl ester of $N-\{(4 R)-4-[4 \alpha-(2-$ carboxyethyl)-3a $\alpha$-hexahydro - $7 \mathrm{a} \beta$ - methyl -5 - oxoindan $-1 \beta$ - yl]valeryl $\}-\mathrm{L}$ homoserine $\gamma$-lactone $(\mathrm{X})$ on the basis of its source and the i.r. and n.m.r. spectra (see under 'Partial syntheses of the conjugates' in the Experimental section). Another minor one was the expected dimethyl ester of the $O$-acetyl-L-homoserine conjugate (III $c$ ). The behaviour on t.l.c. and the i.r. and n.m.r. spectra were identical with those of the dimethyl ester of the $O$ acetylhomoserine conjugate obtained from growing cultures.

L-Glutamine conjugate (IIId). As the first object of partial synthesis, the structure $N^{\alpha}-\{(4 R)-4-[4 \alpha-(2-$ carboxyethyl) - 3a $\alpha$ - hexahydro - 7a $\beta$ - methyl - 5 oxoindan-1 $\beta$-yl]valeryl\}-L-glutamine (III $d$ ) was chosen from the six possible formulations assigned to the fourth metabolite for the ease of preparation. The condensation of the half-ester (VIII) with L-glutamine afforded the corresponding L-glutamine conjugate (IIId) as an amorphous powder. Fortunately, the behaviour on t.l.c. and the i.r. spectrum were identical with those of the fourth metabolite obtained from growing cultures. Further, there was no difference in the behaviour on t.l.c. and the i.r. and n.m.r. spectra between the respective dimethyl esters of both the synthetic and isolated samples.

\section{Experimental}

\section{General}

Methods for incubation, centrifugation and physical measurements were as described by Hayakawa et al. (1969). Unless otherwise stated, optical rotations and i.r.-absorption spectra were determined in chloroform solution.

\section{Chromatography}

Details of adsorption column chromatography were given by Hayakawa et al. (1969), except where otherwise indicated. Methods for t.l.c. and reversedphase partition chromatography were as described in the preceding paper (Hayakawa et al., 1976b), except that cyclohexane/ethyl acetate/acetic acid $(5: 5: 1$, by vol.) was used as a developing solvent system for both analytical and preparative t.l.c. and that both the solvent systems F1 and F2 were used for partition chromatography [for a ratio of solvents, see Sjövall (1964)].

Ion-exchange chromatography for the detection of amino acids was carried out on a Hitachi modified type-II automatic amino acid analyser. The analyser was operated with either a $0.2 \mathrm{M}$-sodium citrate buffer solution of pH3.25 or a $0.35 \mathrm{M}$-sodium citrate buffer solution of pH5.28 at $50^{\circ} \mathrm{C}$, and other operating conditions were described in each case.

\section{Micro-organism}

Corynebacterium equi Magnusson (I.I.D. Ko-85) was a gift from Miss Sawa of The Institute of Medical Science (formerly The Institute for Infectious Diseases), University of Tokyo. Stock cultures were maintained on nutrient-agar slopes at $4^{\circ} \mathrm{C}$ and subcultured every $2-3$ months.

\section{Media}

A synthetic medium was prepared by addition of the"disodium salt of the oxodicarboxylic acid (II) (1 or $3 \mathrm{~g}$ ) or the sodium salt of the $5 \beta$-dihydroxy acid (VI) $(1 \mathrm{~g})$ to a mineral solution (1 litre) which contained $(\mathrm{g} / \mathrm{l}):\left(\mathrm{NH}_{4}\right)_{2} \mathrm{SO}_{4}, 2 ; \mathrm{KH}_{2} \mathrm{PO}_{4}, 1 ; \mathrm{MgSO}_{4}, 7 \mathrm{H}_{2} \mathrm{O}$, $0.5 ; \mathrm{KCl}, 0.5 ; \mathrm{FeSO}_{4}, 7 \mathrm{H}_{2} \mathrm{O}, 0.01$ [for compounds (II) and (VI), see under 'Other materials' below]. In some cases the media were supplemented with yeast extract $(0.5 \mathrm{~g} / 1$; Difco Laboratories, Detroit, MI, U.S.A.) to obtain a better growth. All the media were adjusted to $\mathrm{pH} 7.4$ with $1 \mathrm{M}-\mathrm{NaOH}$, and the $100 \mathrm{ml}$ amounts of medium in a $500 \mathrm{ml}$ shake-flask were sterilized by autoclaving $\left(1 \mathrm{~kg} / \mathrm{cm}^{2}\right.$ for $\left.20 \mathrm{~min}\right)$.

\section{Other materials}

(4R)-4-[4 $\alpha$-(2-Carboxyethyl)-3a $\alpha$-hexahydro-7a $\beta$ methyl-5-oxoindan-1 $\beta$-yl]valeric acid (II) (Hayakawa et al., 1969), (4R)-4-[3a $\alpha$-hexahydro-5 $\beta$-hydroxy- $4 \alpha$ (3-hydroxypropyl) -7a $\beta_{1}$ - methylindan $-1 \beta$-yl]valeric acid (VI) (Hayakawa et al., 1976a) and (4R)-4$(2,3,4,6,6 \mathrm{a} \beta, 7,8,9,9 \mathrm{a} \alpha, 9 \mathrm{~b} \beta$-decahydro-6a $\beta$-methyl-3oxo-1 $H$ - cyclopenta[f]quinolin $-7 \beta$-yl)valeric acid (IV) (Hayakawa et al., 1976b) were prepared as reported previously. Amino acids were purchased from Sigma Chemical Co. (St. Louis, MO, U.S.A.). $N$-2,4-Dinitrophenyl-L-alanine was prepared from Lalanine and 1-fluoro-2,4-dinitrobenzene by the method of Sanger (1945), and had m.p. $172-175^{\circ} \mathrm{C}$ and $[\alpha]_{\mathrm{D}}^{23}+136.6 \pm 2.5^{\circ}(c 0.715$ in $1 \mathrm{M}-\mathrm{NaOH})$. It showed $\lambda_{\max }$ (in $\left.1 \mathrm{M}-\mathrm{HCl}\right) 266(\varepsilon 8500)$ and $354 \mathrm{~nm}$ ( $\varepsilon$ 15500) and i.r. max. (in Nujol) at 3350, 3088, approx. 2400-2800, 1720, 1680,1624, 1590, 1524, $1505,1460,1414$ and $1361 \mathrm{~cm}^{-1}$ (Found: $\mathrm{C}, 42.5 ; \mathrm{H}$, 3.6; $\mathrm{N}, 16.5$. Calc. for $\mathrm{C}_{9} \mathrm{H}_{9} \mathrm{~N}_{3} \mathrm{O}_{6}: \mathrm{C}, 42.4 ; \mathrm{H}, 3.6 ; \mathrm{N}$, 16.5). Rao \& Sober (1954) give m.p. $177^{\circ} \mathrm{C}$ and $[\alpha]_{\mathrm{D}}+144^{\circ}$ (in $1 \mathrm{M}-\mathrm{NaOH}$ and at $25 \pm 1^{\circ} \mathrm{C}$ ) for this compound. Although the above i.r. bands could not be fully assigned to the respective functional groups, the presence of bands at $3350(\mathrm{NH})$ and $1720(\mathrm{C}=\mathrm{O}$ 
of $\left.\mathrm{CO}_{2} \mathrm{H}\right) \mathrm{cm}^{-1}$ suggested that the sample did not exist completely in zwitterion form. $\alpha$-Amino- $\gamma$ butyrolactone hydrochloride as an authentic sample for the amino acid analyser was prepared by heating a solution of L-homoserine (approx. $1 \mathrm{mg}$ ) in a few drops of dilute $\mathrm{HCl}$ at approx. $80^{\circ} \mathrm{C}$ for several minutes, followed by vacuum-drying. The sample was contaminated with approx. $5 \%(\mathrm{w} / \mathrm{w}) \mathrm{L}$-homoserine hydrochloride as indicated by the amino acid analyser. Other materials were obtained from commercial sources and where necessary recrystallized or distilled before use. Light petroleum had b.p. 40$60^{\circ} \mathrm{C}$.

\section{Incubation of the oxodicarboxylic acid (II) with C. equi}

The 2-day-old culture broth $(2 \mathrm{ml})$ of $C$. equi, precultured in a medium containing both the $5 \beta$ dihydroxy acid (VI) $(1 \mathrm{~g} / \mathrm{l})$ and yeast extract $(0.5 \mathrm{~g} / \mathrm{l})$ as carbon sources, was transferred to the shake-flask containing an incubation medium $(100 \mathrm{ml})$ that contained the oxodicarboxylic acid (II) $(3 \mathrm{~g} / \mathrm{l})$ as the sole source of carbon. The inoculated flasks were incubated, and the course of the degradation of the acid (II) was monitored by t.l.c. as described for the degradation of cholic acid by $A$. simplex (Hayakawa et al., 1969). When the result of t.l.c. indicated both the new appearance of the more polar products than the acid (II) and the residual presence of a small amount of the unaltered acid (II), the incubation was stopped. The incubation was usually continued for approx. $40-50 \mathrm{~h}$.

\section{Extraction and fractionation of the metabolites}

The incubation mixture, which was judged by the result of t.l.c., was centrifuged to remove the cells. The cell-free supernatant (approx. 20 litres), resulting from the consumption of the acid (II) $(60 \mathrm{~g})$, was acidified with dilute $\mathrm{HCl}$ to $\mathrm{pH}$ approx. 4 and extracted three times with 6-litre portions of chloroform. The extract was washed with water, dried over anhydrous $\mathrm{Na}_{2} \mathrm{SO}_{4}$ and then evaporated in vacuo to yield a crystalline residue $(6.63 \mathrm{~g})$. The washings were combined with the aqueous layer. On recrystallization from acetone, the residue recovered the unaltered acid (II) (4.53 g). The mother liquor, after evaporation of the solvent, was subjected to chromatography on silicic acid $(85 \mathrm{~g})$. Elution with ether yielded also the acid (II) (1.6g).

The aqueous layer, after removal of the chloroformsoluble materials, was neutralized with $5 \%(w / v)$ $\mathrm{NaHCO}_{3}$ to $\mathrm{pH}$ approx. 7.5 and concentrated in vacuo to approx. 1 litre. The concentrate was acidified with dilute $\mathrm{HCl}$ to $\mathrm{pH}$ approx. 2 and extracted with ethyl acetate. The extract was evaporated in vacuo at room temperature to afford a gum $(4.99 \mathrm{~g})$, which consisted of a complex mixture of metabolites as indicated by t.l.c. It was dissolved in a minimal volume of acetone and mixed well with silicic acid (10g). The mixture was air-dried and then completely dried in vacuo to afford a powder, which was placed on the top of a column of silicic acid $(200 \mathrm{~g})$ prepared in ether. Elution with $500 \mathrm{ml}$ portions of solvents of various polarities was performed and part of each fraction collected was examined by t.l.c. Fractions that were similar to each other in behaviour on t.l.c. were pooled, and evaporation of the solvents in vacuo afforded the following pattern: pool $A$ (fraction no. 1 and no. 2 eluted with ether), 1.797g; pool $B$ (fraction no. 3 eluted with ether), $385 \mathrm{mg}$; pool $C$ [fraction no. 4 eluted with ethyl acetate/ether $(1: 199, \mathrm{v} / \mathrm{v})$ ], $115 \mathrm{mg} ;$ pool $D$ [from fraction no. 5 to no. 7 eluted with ethyl acetate/ether $(1: 199, \mathrm{v} / \mathrm{v})]$, $482 \mathrm{mg}$; pool $E$ [fraction no. 8 and no. 9; from no. 10 to no. 13 ; no. 14 and no. 15 ; no. 16 and no. 17 ; no. 18 and no. 19; no. 20 and no. 21 ; no. 22 and no. 23 ; and no. 24 and no. 25 eluted with ethyl acetate/ether $(1: 199, \mathrm{v} / \mathrm{v}) ;(1: 99, \mathrm{v} / \mathrm{v}) ;(1: 49, \mathrm{v} / \mathrm{v}) ;(3: 97, \mathrm{v} / \mathrm{v}) ;(1: 19$, $\mathrm{v} / \mathrm{v}) ;(1: 9, \mathrm{v} / \mathrm{v}),(1: 4, \mathrm{v} / \mathrm{v})$ and $(1: 1, \mathrm{v} / \mathrm{v})$ respectively], $1.199 \mathrm{~g}$; pool $F$ (fraction no. 26 and no. 27 eluted with ethyl acetate), $47 \mathrm{mg}$; and pool $G$ (fraction no. 28 and no. 29 eluted with acetone and methanol respectively), $718 \mathrm{mg}$.

\section{Isolation of the metabolites}

Pool $A$ was a complex mixture of products, which mainly consisted of less polar products than the oxodicarboxylic acid (II). Attempts to isolate any components in a pure form were unsuccessful, except for the recovery of the acid (II) (63 mg, m.p. 165$167^{\circ} \mathrm{C}$ ). Both pools $B$ and $C$ mainly consisted of the products that move more slowly on t.l.c. than the acid (II) but faster than the L-alanine conjugate, and they were not further treated.

(a) Isolation of the L-alanine conjugate (IIIa) from pool $D$. The pool $(482 \mathrm{mg})$, which mainly consisted of a metabolite having $R_{F} \mathbf{0 . 2 1}$ on t.l.c., was dissolved in water (approx. $5 \mathrm{ml}$ ) with the aid of a minimal amount of $5 \%(\mathrm{w} / \mathrm{v}) \mathrm{NaHCO}_{3}$. Ether (approx. $5 \mathrm{ml}$ ) was then layered over the solution and thoroughly mixed. The mixture was acidified with dilute $\mathrm{HCl}$ to cause incipient cloudiness and kept overnight in a refrigerator. The prismatic crystals $(38 \mathrm{mg})$ of $N-\{(4 R)-4$ -

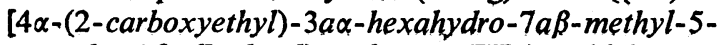
oxoindan-1 $\beta$-yl]valeryl $\}$-L-alanine (III $a$ ), which crystallized out in the aqueous layer, were filtered, washed with water and then with ether and dried. It had m.p. 161.5-163.5 $\mathrm{C}$ and $[\alpha]_{D}^{24}+11.0 \pm 0.5(c 1.006$ in ethanol) and showed i.r. max. (in Nujol) at 3460 (NH), approx. 2500 and approx. $3200\left(\mathrm{OH}\right.$ of $\left.\mathrm{CO}_{2} \mathrm{H}\right)$, $1740\left(\mathrm{C}=\mathrm{O}\right.$ of $\left.\mathrm{CO}_{2} \mathrm{H}\right), 1700(\mathrm{C}=\mathrm{O})$ and 1617 and 1551 (CONH) $\mathrm{cm}^{-1}$ [Found: C, 63.8; H, 8.2; N, 3.8; $\mathrm{C}_{21} \mathrm{H}_{33} \mathrm{NO}_{6}$ (mol.wt. 395.48) requires, $\mathrm{C}, 63.8 ; \mathrm{H}$, $8.4 ; \mathrm{N}, 3.5 \%$; equiv.wt. (two $\mathrm{CO}_{2} \mathrm{H}$ groups), 380 ]. The mother liquor was neutralized with $5 \%(\mathrm{w} / \mathrm{v})$ $\mathrm{NaHCO}_{3}$ and evaporated in vacuo to yield a residue, which, after treatment by the crystallization method 
of compound (III a) described above, yielded also compound (III a) (145 mg, m.p. 157-160 $0^{\circ} \mathrm{C}$ ).

The dimethyl ester, prepared with ethereal diazomethane, could not be induced to crystallize, but it ran as one spot $\left(R_{F}, 0.35\right)$ on t.l.c. and showed i.r. bands at $3430(\mathrm{NH}), 1737$ (ester), $1703(\mathrm{C}=0)$ and 1671 and 1503 (CONH) $\mathrm{cm}^{-1}$ and n.m.r. absorptions at approx. $0.93(3 \mathrm{H}$; superimposable doublet; $\mathrm{Me}$ in the valeric acid side chain), 0.99 (3H; singlet; $7 \mathrm{a} \beta$-Me), $1.39(3 \mathrm{H}$; doublet; $J 7.2 \mathrm{~Hz} ; \mathrm{Me}$ in the L-alanine moiety), 3.65 (3H; singlet; $\left.\mathrm{CO}_{2} \mathrm{Me}\right), 3.75$ $\left(3 \mathrm{H}\right.$; singlet; $\left.\mathrm{CO}_{2} \mathrm{Me}\right), 4.60(1 \mathrm{H}$; unsharp pentuplet; $\mathrm{CH}$ in the L-alanine moiety) and $6.04(1 \mathrm{H}$; broad doublet; CONH) p.p.m.

(b) Isolation of the glutamic acid conjugate (IIIb) and $O$-acetylhomoserine conjugate (IIIc) from pool $E$. The pool $(1.199 \mathrm{~g})$ mainly consisted of three metabolites, which showed $R_{F}$ values $0.14,0.19$ and 0.21 on t.l.c. respectively. One $\left(R_{F}, 0.21\right)$ of them was consistent with the above L-alanine conjugate (III $a$ ) on t.l.c. The pool was subjected to reversed-phase partition chromatography (Hostalen S, $230 \mathrm{~g}$; solvent system F1) and part of each fraction $(10 \mathrm{ml})$ was tested by t.l.c. Fractions that are similar to each other in compositions on t.l.c. were pooled, and evaporation of the solvents in vacuo left the following pattern: pool $E-1$ (from fraction no. 1 to no. 9), no detectable amount of materials; pool $E-2$ (from fraction no. 10 to no. 13), $66 \mathrm{mg}$; pool $E-3$ (from fraction no. 14 to no. 21), $184 \mathrm{mg}$; pool $E-4$ (from fraction no. 22 to no. 36), $166 \mathrm{mg}$; pool $E-5$ (from fraction no. 37 to no. 42), $39 \mathrm{mg}$; pool $E-6$ (from fraction no. 43 to no. 65), $233 \mathrm{mg}$; and pool $E-7$ (from fraction no. 66 to no. 93), $62 \mathrm{mg}$. After the elution of fraction no. 93 , the column was further eluted with methanol (approx. $200 \mathrm{ml}$ ), and evaporation of the methanol afforded a residue (pool $E-8,326 \mathrm{mg}$ ).

Pool E-2 (66mg), which mainly consisted of a metabolite having $R_{F} 0.14$ on t.l.c., was treated by the method that was described above for the crystallization of the L-alanine conjugate (III $a$ ) and afforded only a very small amount of crystals. However, another crystalline product $(68 \mathrm{mg})$, which was similar in behaviour on t.l.c. to the crystals obtained from the first run, were obtained from the second run. In this run, the acid (II) $(120 \mathrm{~g})$ was incubated with $C$. equi and the resulting incubation mixture was treated in a manner similar to that described above for the first run. The crystals obtained from the second run, on further recrystallization from methanol/water, afforded the monosodium salt of $N-\{(4 R)-4-[4 \alpha-(2-$

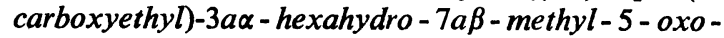
indan-1 $\beta$-yl]valeryl glutamic acid (III $b$ ) as plates, m.p. $114-117^{\circ} \mathrm{C}$ and i.r. $\max$. (in $\mathrm{KBr}$ ) at $3344(\mathrm{NH})$, approx. $2600\left(\mathrm{OH}\right.$ of $\left.\mathrm{CO}_{2} \mathrm{H}\right), 1726$ (shoulder) $\left(\mathrm{C}=\mathrm{O}\right.$ of $\left.\mathrm{CO}_{2} \mathrm{H}\right), 1707(\mathrm{C}=\mathrm{O})$ and 1671,1563 and 1545 (shoulder) (CONH and $\mathrm{CO}_{2}^{-}$) $\mathrm{cm}^{-1}$ (Found: $\mathrm{C}$, $58.5 ; \mathrm{H}, 7.3 ; \mathrm{N}, 3.4 ; \mathrm{Na}, 3.9 ; \mathrm{C}_{23} \mathrm{H}_{34} \mathrm{NO}_{8} \mathrm{Na}$ requires
C, $58.1 ; \mathrm{H}, 7.2 ; \mathrm{N}, 3.0 ; \mathrm{Na}, 4.8 \%$ ). The sample gave no satisfactory analytical values, but it ran as one spot $\left(R_{F} 0.14\right)$ on t.l.c. The salt was suspended in dilute $\mathrm{HCl}$ and extracted with ethyl acetate. Evaporation of the solvent gave the corresponding free acid (IIIb), which could not be induced to crystallize.

The trimethyl ester, prepared from the above free acid with ethereal diazomethane, was a gum. It ran as one spot $\left(R_{F} \mathbf{0 . 3 7}\right)$ on t.l.c. and showed i.r. bands at $3400(\mathrm{NH}), 1738$ (ester), $1704(\mathrm{C}=0)$ and 1675 and $1500(\mathrm{CONH}) \mathrm{cm}^{-1}$ and n.m.r. absorptions at approx. $0.933 \mathrm{H}$; superimposable doublet; $\mathrm{Me}$ in the side chain), $0.99(3 \mathrm{H}$; singlet; $7 \mathrm{a} \beta-\mathrm{Me}), 3.65(3 \mathrm{H}$; singlet; $\left.\mathrm{CO}_{2} \mathrm{Me}\right), 3.68\left(3 \mathrm{H}\right.$; singlet; $\left.\mathrm{CO}_{2} \mathrm{Me}\right), 3.74(3 \mathrm{H}$; singlet; $\left.\mathrm{CO}_{2} \mathrm{Me}\right), 4.60(1 \mathrm{H}$; multiplet; $\mathrm{CH}$ in the glutamic acid moiety) and $6.20(1 \mathrm{H}$; broad doublet; CONH) p.p.m.

Pool E-3 mainly consisted of both compounds (III $a$ ) and (III $b$ ), and pool $E-5$ contained mainly both compound (III $a$ ) and the $O$-acetylhomoserine conjugate described below, as indicated by t.l.c. These were not subjected to further purification. Pool $E-4$ was treated by the above crystallization method of compound (III $a$ ) and yielded compound (III $a$ ) (28 mg).

Pool E-6 (233 mg) was further submitted to reversed-phase partition chromatography (Hostalen $\mathrm{S}, 80 \mathrm{~g}$; solvent system $\mathrm{F} 2$ ), and the $4 \mathrm{ml}$ amounts of each fraction were collected, yielding 48 fractions. Fractions no. 34 and no. 35 which gave a practically single spot $\left(R_{F} 0.19\right)$ on t.l.c., were combined, and evaporation of the solvents left an amorphous powder $(41 \mathrm{mg})$. It moved as two spots $\left(R_{F} 0.33\right.$ and 0.40 ) on t.l.c. after methylation with ethereal diazomethane. However, another sample $(75 \mathrm{mg})$, which ran as one spot on t.l.c. in both the free acid $\left(R_{F} 0.19\right)$ and methyl ester $\left(R_{F} 0.40\right)$ forms, was obtained from the second run, which was described above in the isolation of compound (IIIb). The latter sample, on esterification with ethereal diazomethane, yielded $O$-acetyl $-N-\{(4 R)-4-[4 \alpha-(2-$ carboxyethyl $)-3 a \alpha-$ hexahydro $-7 a \beta$ - methyl -5 - oxoindan $-1 \beta$ - ylvaleryl $\}$ homoserine (IIIc) dimethylester as an oil, which showed i.r. bands at $3430(\mathrm{NH}), 1737(\mathrm{C}=\mathrm{O}$ of ester and acetate), $1703(\mathrm{C}=0)$ and 1676 and $1502(\mathrm{CONH}) \mathrm{cm}^{-1}$ and n.m.r. absorptions at approx. $0.93(3 \mathrm{H}$; superimposable doublet; $\mathrm{Me}$ in the side chain), 0.99 (3H; singlet; $7 \mathrm{a} \beta-\mathrm{Me}), 2.03(3 \mathrm{H}$; singlet; OAc), $3.65(3 \mathrm{H}$; singlet; $\left.\mathrm{CO}_{2} \mathrm{Me}\right), 3.76\left(3 \mathrm{H}\right.$; singlet; $\left.\mathrm{CO}_{2} \mathrm{Me}\right), 4.13$ $\left(2 \mathrm{H}\right.$; triplet; $\mathrm{CH}_{2} \mathrm{OAc}$ in the $\mathrm{O}$-acetylhomoserine moiety), 4.67 (1H; multiplet; $\mathrm{CH}$ in the $O$-acetylhomoserine moiety) and $6.11(1 \mathrm{H}$; broad peak; CONH) p.p.m.

The above sample isolated from the first run was esterified with ethereal diazomethane. The behaviour on t.l.c. was identical with that of a mixture of the respective methyl esters of the above $O$-acetylhomoserine conjugate (IIIc) and the $\alpha$-amino- $\gamma$-butyro- 
lactone conjugate $(\mathrm{X})$, which was isolated as a byproduct in the partial synthesis of compound (IIIc) as described below.

Pools $E-7$ and $E-8$ were not further treated, since they were an intractable mixture of products, which consisted of less polar products than compound (III a). Pool $F$ mainly comprised compounds (III $a$ ), (IIIb) and (IIIc), as indicated by t.l.c.

(c) Isolation of the glutamine conjugate (IIId) from pool $G$. The pool $(718 \mathrm{mg})$ was further fractionated by reversed-phase partition chromatography (Hostalen S, 150g; solvent system F1). Part of each fraction (6ml) was examined by t.l.c., and fractions (from fraction no. 34 to no. 42), which mainly contained a product having $R_{F} \mathbf{0 . 0 4}$, were pooled. Evaporation of the solvent left a crude sample of $N^{\alpha}-\{(4 R)-4[4 \alpha-$

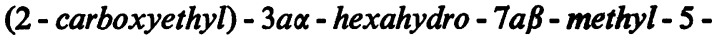
oxoindan-1 $\beta$-yl]valeryl )glutamine (IIId) as an amorphous powder $(77 \mathrm{mg})$.

A portion ( $34 \mathrm{mg}$ ) of the above sample was subjected to preparative t.l.c. (one plate) after methylation with ethereal diazomethane. A main band $\left(R_{F}, 0.09\right)$, as revealed by spraying with water, was scraped from the plate and extracted with chloroform/ methanol $(1: 1, v / v)$. Evaporation of the solvents afforded the corresponding dimethyl ester as a colourless oil ( $9 \mathrm{mg}$ ), which showed i.r. bands at 3455 (weak), 3416 (strong), 3335 (broad, weak) and 3195 (weak) (NH), 1735 (ester), $1704(\mathrm{C}=0)$ and 1678, 1602 and 1504 (CONH ${ }_{2}$ and CONH) $\mathrm{cm}^{-1}$ and n.m.r. absorptions at approx. $0.93(3 \mathrm{H}$; superimposable doublet; $\mathrm{Me}$ in the side chain), 0.98 (3H; singlet; $7 \mathrm{a} \beta-\mathrm{Me})$, 3.65 (3H; singlet; $\left.\mathrm{CO}_{2} \mathrm{Me}\right), 3.75$ (3H; singlet; $\left.\mathrm{CO}_{2} \mathrm{Me}\right)$, approx. $4.59(1 \mathrm{H}$; multiplet; $\mathrm{CH}$ in the glutamine moiety), 6.05 (1H; broad peak; CONH) and $6.58\left(2 \mathrm{H}\right.$; broad peak; $\left.\mathrm{CONH}_{2}\right)$ p.p.m.

\section{Demonstration of each component of the conjugates}

Isolation and characterization of components of the L-alanine conjugate (IIIa). A solution of the conjugate $(59 \mathrm{mg})$ in $6 \mathrm{M}-\mathrm{HCl}(5 \mathrm{ml})$ was heated in a sealed evacuated glass tube at $100-105^{\circ} \mathrm{C}$ for $16 \mathrm{~h}$. The brownish prisms $(40 \mathrm{mg})$ that were precipitated on cooling were filtered, washed with water and then dried. The mother liquor was used for the analysis of amino acids. The crystals were decolorized with activated charcoal powder in approx. $90 \%(\mathrm{v} / \mathrm{v})$ methanol and then recrystallized from acetone to afford the oxodicarboxylic acid (II) as prisms (18 $\mathrm{mg}$ ), m.p. $164.5-167^{\circ} \mathrm{C}$ and $[\alpha]_{\mathrm{D}}^{25}+26.5 \pm 1.6^{\circ}$ (c 0.415$)$ (Found: C, 66.7; $\mathrm{H}, 8.8$. Calc. for $\mathrm{C}_{18} \mathrm{H}_{28} \mathrm{O}_{5}$ : C, 66.6; $\mathrm{H}, 8.7 \%$ ). Identity with an authentic sample was established by mixed m.p. and by comparison of the $[\alpha]_{D}$ and the i.r. spectrum.

A small sample of the mother liquor was evaporated in vacuo to dryness, redissolved in a small volume of water and then subjected to analysis in the amino acid analyser. The sample yielded one peak at the elution volume $107 \mathrm{ml}$ that was identical with that of L-alanine (a buffer solution of pH3.25, a $50 \mathrm{~cm}$ column and an elution rate of $30 \mathrm{ml} / \mathrm{h}$ ). The remaining mother liquor was thoroughly extracted with ether. Evaporation of the ether gave the crude acid (II) (7mg), The aqueous layer was evaporated in vacuo to yield a crystalline residue. The residue was redissolved in water $(0.75 \mathrm{ml})$ containing $\mathrm{NaHCO}_{3}(60 \mathrm{mg})$, and a solution of 1-fluoro-2,4-dinitrobenzene $(60 \mathrm{mg})$ in ethanol $(1.5 \mathrm{ml})$ was added. The mixture was stirred for $2 \mathrm{~h}$ at room temperature and then extracted with ether to remove the excess of 1-fluoro-2,4-dinitrobenzene. The yellowish crystals that were precipitated on acidification of the aqueous layer with dilute $\mathrm{HCl}$ were filtered, washed with water and then dried. Recrystallization from methanol/water afforded $N$-2,4-dinitrophenyl-L-alanine (17 mg), m.p. 170$172.5^{\circ} \mathrm{C}$ and $[\alpha]_{\mathrm{D}}^{24}+155.1 \pm 16.6^{\circ}(\mathrm{c} 0.118$ in $1 \mathrm{M}-$ $\mathrm{NaOH}$ ) (Found: $\mathrm{C}, 42.8 ; \mathrm{H}, 3.5 ; \mathrm{N}, 16.4$. Calc. for $\mathrm{C}_{9} \mathrm{H}_{9} \mathrm{~N}_{3} \mathrm{O}_{6}: \mathrm{C}, 42.4 ; \mathrm{H}, 3.6 ; \mathrm{N}, 16.5 \%$ ). Identity with an authentic sample was established by mixed m.p. and by comparison of the behaviour on t.l.c., the $[\alpha]_{D}$ and the u.v. and i.r. spectra.

Isolation and characterization of components of the conjugates (IIIb), (IIIc) and (IIId). Although these conjugates could not be isolated as analytically pure forms, each sample (approx. $5 \mathrm{mg}$ ), which behaved as a practically single spot on t.l.c., was treated with $6 \mathrm{M}-\mathrm{HCl}$ (approx. $1 \mathrm{ml}$ ) without further purification, as described above in the hydrolysis of compound (III a). A crude sample of the conjugate (IIIc) isolated from the first run was also subjected to this hydrolysis. The acid (II) was commonly extracted with ether from all four hydrolysates and its identity with an authentic sample was established by mixed m.p. and by t.l.c.

The respective aqueous mother liquors, after each removal of compound (II), were separately evaporated in vacuo to dryness and submitted to analysis in the amino acid analyser. The hydrolysate of compound (III $b$ ) yielded one peak at the elution volume $70 \mathrm{ml}$, which is identical with that of L-glutamic acid (a buffer solution of pH3.25, a $50 \mathrm{~cm}$ column and an elution rate of $40 \mathrm{ml} / \mathrm{h}$ ). Both the hydrolysates of two samples of compound (IIIc) isolated from both the first and second runs yielded the following same peaks: two peaks at the elution volume $67 \mathrm{ml}$ (a buffer solution of $\mathrm{pH} 3.25$, a $50 \mathrm{~cm}$ column and an elution rate of $30 \mathrm{ml} / \mathrm{h}$ ) and at $92 \mathrm{ml}$ (a buffer solution of pH 5.28, a $15 \mathrm{~cm}$ column and an elution rate of $30 \mathrm{ml} /$ h). The former was a minor peak and the latter a major one. These peaks were identical in elution volume with those of $L$-homoserine and $\alpha$-amino- $\gamma$ butyrolactone respectively. The hydrolysate of compound (IIId) yielded two main peaks. One of them was identical with the peak of L-glutamic acid [for conditions, see above for the hydrolysate of compound (III b)], and another one at the elution volume $70 \mathrm{ml}$ was identical with that of ammonia (a buffer 
solution of $\mathrm{pH} 5.28$, a $12 \mathrm{~cm}$ column and an elution rate of $30 \mathrm{ml} / \mathrm{h}$ ).

\section{Partial syntheses of the conjugates}

$\mathrm{L}$-Alanine conjugate (IIIa). (a) From the enaminolactam acid (IV). To a solution of the acid $(2.433 \mathrm{~g})$ in anhydrous dioxan $(150 \mathrm{ml})$ containing tri- $n$-butylamine $(2 \mathrm{ml})$ was added ethyl chloroformate $(0.91 \mathrm{ml})$, with cooling to approx. $10^{\circ} \mathrm{C}$. A solution of L-alanine $(784 \mathrm{mg})$ in $1 \mathrm{M}-\mathrm{NaOH}(8.8 \mathrm{ml})$ was added immediately to the mixture and rapidly stirred at room temperature for $4 \mathrm{~h}$. Evaporation of the solvents left a syrup, which was suspended in dilute $\mathrm{HCl}(50 \mathrm{ml})$ and extracted with ethyl acetate. The extract was washed with water, dried over anhydrous $\mathrm{Na}_{2} \mathrm{SO}_{4}$ and evaporated in vacuo to afford a residue $(2.958 \mathrm{~g})$. The residue was treated by the crystallization method described above in the isolation of compound (III $a$ ) from pool $D$, and yielded a crystalline powder $(2.054 \mathrm{~g})$. Repeated recrystallization from methanol/ ethyl acetate and then from acetone afforded $N$ $[(4 R)-4-(2,3,4,6,6 a \beta, 7,8,9,9 a \alpha, 9 b \beta$ - decahydro $-6 a \beta-$ methyl - 3 - oxo - $1 \mathrm{H}$ - cyclopenta[ $[$ ] quinolin $-7 \beta-y l)$ valeryl]-L-alanine $(\mathrm{V})(380 \mathrm{mg})$ with m.p. $181-184^{\circ} \mathrm{C}$. An analytical sample, further recrystallized from acetone, had m.p. $185.5-186.5^{\circ} \mathrm{C},[\alpha]_{\mathrm{D}}^{25}+111.5 \pm 1.7^{\circ}$ (c 0.889 in ethanol) and $\lambda_{\max }$. (in ethanol) $231 \mathrm{~nm}(\varepsilon$ 13100) (Found: $\mathrm{C}, 67.0 ; \mathrm{H}, 8.7 ; \mathrm{N}, 7.4 ; \mathrm{C}_{21} \mathrm{H}_{32} \mathrm{~N}_{2} \mathrm{O}_{4}$ requires $\mathrm{C}, 67.0 ; \mathrm{H}, 8.6 ; \mathrm{N}, 7.4 \%$. The combined mother liquor was subjected to column chromatography on a mixture of silicic acid (114g) and Celite $(6 \mathrm{~g})$ after evaporation of the solvents. Elution with acetone/chloroform $(1: 4, \mathrm{v} / \mathrm{v})$ allowed recovery of the starting material $(809 \mathrm{mg})$, and that with acetone/ chloroform (3:7, v/v) afforded the crude product $(863 \mathrm{mg})$. The latter, on recrystallization from acetone, also yielded compound (V) ( $351 \mathrm{mg}, \mathrm{m} . \mathrm{p}$. $\left.181-184^{\circ} \mathrm{C}\right)$.

A solution of the above L-alanine conjugate (200 $\mathrm{mg})$ in dioxan $(4 \mathrm{ml})$ containing $0.1 \mathrm{M}-\mathrm{HCl}$ $(0.5 \mathrm{ml})$ was heated on a boiling-water bath. After $8 \mathrm{~h}$ of heating, the mixture was evaporated in vacuo to yield a residue. It was suspended in a small volume of water and then extracted with ethyl acetate. The extract was washed with water, dried over anhydrous $\mathrm{Na}_{2} \mathrm{SO}_{4}$ and then evaporated in vacuo to yield a gum (198mg), which was subjected to preparative t.l.c. (six plates). The faster-moving band $\left(R_{F} 0.26\right)$, which was one of the two main bands as revealed by exposure to $I_{2}$ vapour, coincided in positions with that of the starting material. The slower-moving band $\left(R_{F} \mathbf{0 . 2 1}\right)$ was scraped from the plates and extracted with chloroform/methanol/0.01 M-HCl $(10: 10: 1$, by vol.). The solvents were evaporated with a stream of $\mathrm{N}_{2}$ at room temperature to yield a crystalline solid $(137 \mathrm{mg})$. Repeated recrystallization from acetone afforded an analytical sample of $N-\{(4 R)-4-[4 \alpha-(2-$

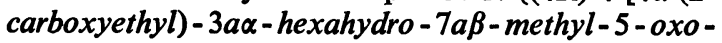

indan- $1 \beta-y$ l]valeryl $\}$-L-alanine (IIIa), m.p. $161-163^{\circ} \mathrm{C}$ and $[\alpha]_{\mathrm{D}}^{24}+10.6 \pm 0.8^{\circ}$ (c0.659 in ethanol)(Found: $C$, $63.9 ; \mathrm{H}, 8.4 ; \mathrm{N}, 3.6 ; \mathrm{C}_{21} \mathrm{H}_{33} \mathrm{NO}_{6}$ requires $\mathrm{C}, 63.8 ; \mathrm{H}$, $8.4 ; \mathrm{N}, 3.5 \%$ ). Identity with the metabolite (III $a$ ) isolated from growing cultures was established by mixed m.p. and by comparison of the behaviour on t.l.c., the $[\alpha]_{D}$ and the i.r. spectrum. Further, the behaviour on t.l.c. and the i.r. and n.m.r. spectra of the corresponding oily dimethyl ester of this sample were also identical with those of the dimethyl ester of the isolated sample.

(b) From the $5 \beta$-dihydroxy acid (VI). The acid $(1.041 \mathrm{~g})$ was dissolved in a solution of $N$-hydroxysuccinimide $(384 \mathrm{mg})$ in anhydrous ethyl acetate $(100 \mathrm{ml})$ without heating. A solution of dicyclohexylcarbodi-imide $(688 \mathrm{mg})$ in anhydrous ethyl acetate $(1 \mathrm{ml})$ was added to the solution, and the mixture was kept overnight at room temperature. Dicyclohexylurea, crystallized out in the mixture, was filtered off and the filtrate was evaporated in vacuo to afford a crystalline residue $(1.416 \mathrm{~g})$, which was recrystallized from ethanol to yield 2,5-dioxopyrrolidin-1-yl (4R)-4$[3 a \alpha-h e x a h y d r o-5 \beta$-hydroxy-4 $\alpha-(3-h y d r o x y p r o p y l)-$

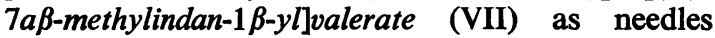
$(911 \mathrm{mg})$, m.p. $144-147.5^{\circ} \mathrm{C},[\alpha]_{\mathrm{D}}^{25}+31.5 \pm 1.4^{\circ}(c$ 0.511 in ethanol) and i.r. max. at 3420 (broad) $(\mathrm{OH})$ and 1808,1783 and 1740 ( $N$-hydroxysuccinimide ester) (Found: $\mathrm{C}, 64.6 ; \mathrm{H}, 8.8 ; \mathrm{N}, 3.6 ; \mathrm{C}_{22} \mathrm{H}_{35} \mathrm{NO}_{6}$ requires $\mathrm{C}, 64.5 ; \mathrm{H}, 8.6 ; \mathrm{N}, 3.4 \%)$.

The $5 \beta$-dihydroxy ester (VII) $(2.716 \mathrm{~g})$ in acetone $(50 \mathrm{ml})$ was treated with Jones reagent $(8 \mathrm{ml})$ at room temperature for $2 \mathrm{~h}$. A small volume of $5 \%(\mathrm{w} / \mathrm{v})$ $\mathrm{NaHSO}_{3}$ was added to the mixture to destroy the excess of $\mathrm{CrO}_{3}$. Then the mixture was neutralized with $5 \%(\mathrm{w} / \mathrm{v}) \mathrm{NaHCO}_{3}$ and concentrated in vacuo to about one-tenth of its original volume. The concentrate was diluted with water, acidified with dilute $\mathrm{HCl}$ and then extracted with ethyl acetate. The extract was washed with saturated $\mathrm{NaCl}$ and dried over anhydrous $\mathrm{Na}_{2} \mathrm{SO}_{4}$. Evaporation of the solvent in vacuo left a residue, which was chromatographed on silicic acid $(120 \mathrm{~g})$. Elution with acetone/chloroform (from $1: 19, \mathrm{v} / \mathrm{v}$, to 1:9, v/v) gave 2,5-dioxopyrrolidin$1-y l(4 R)-4-[4 \alpha-(2$ - carboxyethyl $)-3 a \alpha-h e x a h y d r o-$ $6 a \beta$-methyl-5-oxoindan-1 $\beta$-yl]valerate (VIII), which, after treatment with acetone/light petroleum, formed an amorphous powder $(2.08 \mathrm{~g})$, m.p. $124.5-126^{\circ} \mathrm{C}$, $[\alpha]_{\mathrm{D}}^{21}+21.3 \pm 1.2^{\circ}(c 0.522$ in ethanol) and i.r. max. at approx. 2600-3200 (OH of $\left.\mathrm{CO}_{2} \mathrm{H}\right), 1818,1788$ and $1746(N$-hydroxysuccinimide ester) and $1706(\mathrm{C}=\mathrm{O}$ and $\mathrm{C}=\mathrm{O}$ of $\mathrm{CO}_{2} \mathrm{H}$ ) cm $\mathrm{cm}^{-1}$ (Found: $\mathrm{C}, 62.5 ; \mathrm{H}, 7.5$; $\mathrm{N}, 3.3 ; \mathrm{C}_{22} \mathrm{H}_{31} \mathrm{NO}_{7}$ requires $\mathrm{C}, 62.7 ; \mathrm{H}, 7.4 ; \mathrm{N}, 3.3 \%$ ).

A solution of the above half-ester (VIII) $(825 \mathrm{mg})$ in tetrahydrofuran $(10 \mathrm{ml})$ was added to a solution of L-alanine $(174 \mathrm{mg})$ and $\mathrm{NaHCO}_{3}(164 \mathrm{mg})$ in water $(10 \mathrm{ml})$, with stirring and the mixture kept at room temperature for $20 \mathrm{~h}$. After concentration in vacuo to about one-tenth of its original volume, the con- 
centrate was diluted with water $(2 \mathrm{ml})$, acidified with dilute $\mathrm{HCl}$ to $\mathrm{pH}$ approx. 4 and then extracted with ether. Evaporation of the ether left a residue $(274 \mathrm{mg})$, which mainly consisted of a mixture of the unaltered half-ester (VIII) and the oxodicarboxylic acid (II), as indicated by t.l.c. The aqueous layer was mixed with ether (approx. $1 \mathrm{ml}$ ), acidifled with dilute $\mathrm{HCl}$ to cause incipient cloudiness and then kept overnight in a refrigerator. The prismatic crystals $(343 \mathrm{mg})$ that crystallized out in the aqueous layer were filtered, washed with water and then with ether and dried. Further recrystallization from acetone gave an analytical sample of the L-alanine conjugate (IIIa), m.p. $160.5-161.5^{\circ} \mathrm{C}$ and $[\alpha]_{\mathrm{D}}^{23}+10.0 \pm 1.4^{\circ}(c 0.351$ in ethanol) (Found; $\mathrm{C}, 64.0 ; \mathrm{H}, 8.5 ; \mathrm{N}, 3.4 ; \mathrm{C}_{21} \mathrm{H}_{33} \mathrm{NO}_{6}$ requires $\mathrm{C}, 63.8 ; \mathrm{H}, 8.4 ; \mathrm{N}, 3.5 \%$ ). Identity with the above synthetic sample was determined by mixed m.p. and by comparison of the $[\alpha]_{D}$ and the i.r. spectrum.

L-Glutamic acid conjugate (IIIb). The half-ester (VIII) $(1 \mathrm{~g})$ in tetrahydrofuran $(15 \mathrm{ml})$ was treated with a solution of the disodium salt of L-glutamic acid $(349 \mathrm{mg})$ in water $(15 \mathrm{ml})$, exactly as described above in the preparation of compound (III $a$ ). The resulting aqueous layer, after removal of ether-soluble materials $(463 \mathrm{mg}$ ), was acidified with dilute $\mathrm{HCl}$ to $\mathrm{pH}$ approx. 2 and thoroughly extracted with ethyl acetate. The extract was washed with saturated $\mathrm{NaCl}$, dried over anhydrous $\mathrm{Na}_{2} \mathrm{SO}_{4}$ and then evaporated in vacuo to yield a colourless gum $(567 \mathrm{mg})$, which ran as a practically single spot $\left(R_{P} 0.14\right)$ on t.l.c. When the gum was treated with $5 \%(\mathrm{w} / \mathrm{v}) \mathrm{NaHCO}_{3}$ to make a solution of the corresponding monosodium salt and approx. $1.6 \mathrm{ml}$ of the $\mathrm{NaHCO}_{3}$ solution had been consumed, it became a slurry containing needles. The slurry was diluted with acetone and filtered to collect the crystals $(277 \mathrm{mg})$. The mother liquor was evaporated in vacuo to dryness, treated with $5 \%(w / v)$ $\mathrm{NaHCO}_{3}(1 \mathrm{ml})$ and also yielded crystals $(139 \mathrm{mg})$. The former crystals were recrystallized from water/ acetone to give the disodium salt of $N-\{(4 R)-4-[4 \alpha-(2-$ carboxyethyl) - 3a $\alpha$ - hexahydro - 7a $\beta$ - methyl -5 - oxo indan-1 $\beta-y$ l]valeryl $\}-\mathrm{L}-$ glutamic acid (IIIb) as prisms (186mg), m.p. $188-195^{\circ} \mathrm{C},[\alpha]_{\mathrm{D}}^{22}+18.0 \pm 1.2^{\circ}$ (c 0.471 in water) and i.r. $\max$. (in $\mathrm{KBr}$ ) at $3350(\mathrm{NH})$, approx. $2500\left(\mathrm{OH}\right.$ of $\left.\mathrm{CO}_{2} \mathrm{H}\right), 1705(\mathrm{C}=\mathrm{O}$ and $\mathrm{C}=0$ of $\mathrm{CO}_{2} \mathrm{H}$ ) and 1640,1565 (broad, strong) and 1400 (CONH and $\mathrm{CO}_{2}^{-}$) $\mathrm{cm}^{-1}$ (Found: $\mathrm{C}, 55.8 ; \mathrm{H}, 6.9$; $\mathrm{N}, 3.1 ; \mathrm{Na}, 7.1 ; \mathrm{C}_{23} \mathrm{H}_{34} \mathrm{NO}_{8} \mathrm{Na}$ and $\mathrm{C}_{23} \mathrm{H}_{33} \mathrm{NO}_{8} \mathrm{Na}_{2}$ require $\mathrm{C}, 58.1 ; \mathrm{H}, 7.2 ; \mathrm{N}, 3.0 ; \mathrm{Na}, 4.8 \%$, and $\mathrm{C}$, $55.5 ; \mathrm{H}, 6.7 ; \mathrm{N}, 2.8 ; \mathrm{Na}, 9.3 \%$ respectively). The sample gave no satisfactory analytical data, probably owing to the presence of the corresponding monosodium salt, but it ran as one spot on t.l.c. All attempts to prepare the analytically pure corresponding monosodium or trisodium salt and to crystallize the corresponding free acid were unsuccessful.
The trimethyl ester, prepared from the free acid with ethereal diazomethane, could not be induced to crystallize. The behaviour on t.l.c. and the i.r. and n.m.r. spectra were identical with those of the trimethyl ester of the metabolite (IIIb) obtained from growing cultures.

O.Acetyl-L-homoserine conjugate (IIIc). Exactly as described above in the preparation of compound (IIIb), the coupling reaction of the half-ester (VIII) $(1 \mathrm{~g})$ with the sodium salt of L-homoserine $(283 \mathrm{mg})$ was carried out, and ether-soluble materials $(202 \mathrm{mg}$ ) and the corresponding L-homoserine conjugate (IX) $(799 \mathrm{mg})$ were obtained. The latter was contaminated with minute amounts of its $\gamma$-lactone as indicated by the i.r. absorption at $1780 \mathrm{~cm}^{-1}$. It was then sus pended in water (approx. $5 \mathrm{ml}$ ) and treated with $1 \mathrm{M}$ $\mathrm{NaOH}$ (approx. $3.8 \mathrm{ml}$ ) to hydrolyse the lactone ring, yielding a clear solution of pH8. Evaporation of the water in vacuo at room temperature left a crystalline solid, which was recrystallized from water/acetone to afford the disodium salt of $N-\{(4 R)-4-[4 \alpha-(2-c a r b o x y$ -

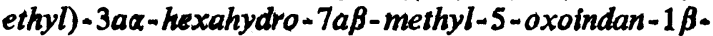
$y[$ valeryl $\}$-L-homoserine (IX) as plates (765 mg), m.p. $155-157^{\circ} \mathrm{C},[\alpha]_{D}^{25}+7.6 \pm 0.5(c 0.986$ in water $)$ and i.r. $\max$. (in $\mathrm{KBr}$ ) at 3400 (broad) (NH and $\mathrm{OH}$ ), 1703 $(C=0)$ and 1650 (shoulder), 1576 (broad) and 1408 (CONH and $\mathrm{CO}_{2}^{-}$) $\mathrm{cm}^{-1}$ (Found: $\mathrm{C}, 56.7 ; \mathrm{H}, 7.3$; $\mathrm{N}, 3.1 ; \mathrm{Na}, 10.4 ; \mathrm{C}_{22} \mathrm{H}_{33} \mathrm{NO}_{7} \mathrm{Na}_{2}$ requires $\mathrm{C}, 56.3$; $\mathrm{H}, 7.1 ; \mathrm{N}, 3.0 ; \mathrm{Na}, 9.8 \%)$. The sample gave no satisfactory analytical values, but it ran as one spot $\left(R_{F}\right.$ 0.12) on t.l.c.

The above disodium salt $(500 \mathrm{mg})$ was dissolved in a chilled solution $(2.12 \mathrm{ml})$ at $0^{\circ} \mathrm{C}$ consisting of $70 \%$ $(\mathrm{w} / \mathrm{v}) \mathrm{HClO}_{4}(0.51 \mathrm{ml})$, water $(0.04 \mathrm{ml})$ and acetic acid $(9.45 \mathrm{ml})$, and acetic anhydride $(0.48 \mathrm{ml})$ was then added dropwise with stirring. After $3.5 \mathrm{~h}$ of the stirring at room temperature, the mixture was diluted with water (approx. $10 \mathrm{ml}$ ) and treated with a drop of pyridine to destroy the acetic anhydride and to neutralize the $\mathrm{HClO}_{4}$. After concentration to about one-tenth of its original volume with a stream of $\mathrm{N}_{2}$ at room temperature, it was thoroughly extracted with ethyl acetate. The extract was washed with water, dried over anhydrous $\mathrm{Na}_{2} \mathrm{SO}_{4}$ and then evaporated in vacuo to yield a gum. After esterification with ethereal diazomethane, it was chromatographed on silica gel (21 g) that had been previously deactivated by the addition of water $(5 \%, w / w)$. Elution with ether saturated with water gave $O$-acetyl- $N-\{(4 R)-4$

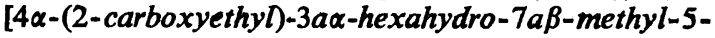
oxoindan-1 $\beta-y$ l] valeryl $\}$-L-homoserine (IIIc) dimethyl ester as a colourless oil $(78 \mathrm{mg})$. The behaviour on t.l.c. and the i.r. and n.m.r. spectra were identical with those of the dimethyl ester of the metabolite (IIIc) obtained from growing cultures.

Further elution with ethyl acetate/ether (from 1:9, $\mathrm{v} / \mathrm{v}$, to $1: 1, \mathrm{v} / \mathrm{v})$ and ethyl acetate gave $N-\{(4 R)-4$

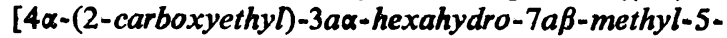


oxoindan-1 $\beta$-yl]valeryl\}-L-homoserine y-lactone (X) methyl ester as a colourless oil ( $349 \mathrm{mg}$ ), which showed i.r. $\max$. at $3340(\mathrm{NH}), 1780$ (five-membered ring lactone), 1734 (ester), $1703(\mathrm{C}=0)$ and 1680 and 1503 (CONH) $\mathrm{cm}^{-1}$ and n.m.r. absorptions at approx. 0.93 (3H; superimposable doublet; $\mathrm{Me}$ in the side chain), 0.99 ( $3 \mathrm{H}$; singlet, $7 \mathrm{a} \beta-\mathrm{Me}$ ), 3.65 (3H; singlet; $\left.\mathrm{CO}_{2} \mathrm{Me}\right)$, approx. $4.40(3 \mathrm{H}$; multiplet; both $\mathrm{CH}$ and $\mathrm{CH}_{2} \mathrm{O}$ in the $\alpha$-amino- $\mu$-butyrolactone moiety) and 5.99 (1H; broad peak; CONH) p.p.m.

L-Glutamine conjugate (IIId). The half-ester (VIII) (500 mg) was coupled with the sodium salt of Lglutamine (173 $\mathrm{mg})$, exactly as described above in the synthesis of compound (III $b$ ), and ether-soluble materials $(145 \mathrm{mg})$ and the corresponding crude conjugate $(373 \mathrm{mg})$ were obtained. The latter was dissolved in a small volume of methanol, mixed well with silica gel $(400 \mathrm{mg})$ and air-dried to yield a homogeneous powder, which was placed on the top of a column of silicic acid $(15 \mathrm{~g})$ prepared in ether. This silicic acid had been previously deactivated by the addition of water $(5 \%, w / w)$. Elution with methanol/ ether (from $1: 9, \mathrm{v} / \mathrm{v}$, to $1: 4, \mathrm{v} / \mathrm{v})$ gave $N^{\alpha}\{(4 R)-4$

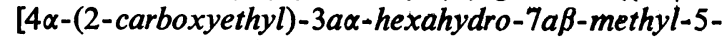
oxoindan-1 $\beta$-yl]valeryl\}-L-glutamine (IIId), which after treatment with methanol/ether formed an amorphous powder $(318 \mathrm{mg})$, m.p. $56-59^{\circ} \mathrm{C},[\alpha]_{\mathrm{D}}^{22}$ $+17.6 \pm 1.0^{\circ}$ ( $c 0.563$ in ethanol) and i.r. max. (in $\mathrm{KBr}$ ) at 3360 and 3220 (shoulder) (NH), approx. 2600 (broad) $\left(\mathrm{OH}\right.$ of $\left.\mathrm{CO}_{2} \mathrm{H}\right), 1727$ (shoulder) and $1713\left(\mathrm{C}=\mathrm{O}\right.$ and $\mathrm{C}=\mathrm{O}$ of $\left.\mathrm{CO}_{2} \mathrm{H}\right)$ and 1622,1627 (shoulder) and 1547 (broad) $\left(\mathrm{CONH}_{2}\right.$ and $\left.\mathrm{CONH}\right) \mathrm{cm}^{-1}$ (Found; C, 60.9; $\mathrm{H}, 8.3 ; \mathrm{N}, 5.9 ; \mathrm{C}_{23} \mathrm{H}_{36} \mathrm{~N}_{2} \mathrm{O}_{7}$ requires $\mathrm{C}, 61.0 ; \mathrm{H}, 8.0 ; \mathrm{N}, 6.2 \%$ ). No signiflcant difference in the i.r. spectrum between the synthetic sample and the isolated metabolite (IIId) was observed, although the latter was contaminated with minute quantities of foreign compounds, as indicated by t.l.c.

The dimethyl ester, prepared with ethereal diazomethane, could not be induced to crystallize. The behaviour on t.l.c. and the i.r. and n.m.r. spectra were identical with those of the dimethyl ester of the metabolite (III $d$ ) obtained from growing cultures.

\section{Discussion}

The results of studies on incubation conditions show that, although not quantitatively, the inoculum of $C$. equi grown on the $5 \beta$-dihydroxy acid (VI) surpasses that grown on the oxodicarboxylic acid (II) with regard to the accumulation of metabolites. We only used compound (VI) as carbon sources of a preculture medium in the hope that, compared with the latter inoculum, the former might have a lower compound-(II)-catabolizing activity and result in the slower degradation of compound (II) and its metabolites. No definite explanation for the biochemical role of compound (VI) in the pre-culture medium can be offered at the present time.

With regard to the origin of the $\alpha$-amino- $\gamma$-butyrolactone conjugate $(\mathrm{X})$ isolated from the first run as a mixture with compound (IIIc), it is unknown whether the conjugate $(\mathrm{X})$ is either a true metabolite or an artifact formed in the isolation process, especially in the extraction process of metabolites under acidic conditions. However, it may be the artifact, and the corresponding parent compound is probably the $O$ acetylhomoserine conjugate (IIIc) or its deacylatated product, the homoserine conjugate (IX) (or both), although the latter was not isolated in the present work.

The results of the above chemical investigations show that the structure of all the isolated metabolites (III $a$ ), (III b), (IIIc) and (III d) consists of two parts, one part being the acid (II) used as the sole source of carbon and energy for the growth of $C$. equi and the other part being an amino acid or its derivative, which is probably a primary or secondary metabolite of this organism. They also indicate that the carboxyl group of the valeric acid side chain in the acid (II) molecule is linked by a peptide bond to the $\alpha$-amino group of alanine, glutamic acid, $O$-acetylhomoserine or glutamine, although the configuration of these amino acids and their derivatives could not be established except for the alanine because of lack of material. Since the alanine was the $L$ isomer, other amino acids and their derivatives probably have the L configuration, but definitive proof must await further investigations.

The occurrence of conjugation of a foreign compound to the body with a substance biosynthesized by the organism has been well known in animals (cf. Williams, 1963). In higher plants, indol-3-ylacetic acid and other carboxylic acids are metabolized to their conjugates with amino acids such as aspartic acid and glutamic acid (cf. Shantz, 1966). In microorganisms, however, little is known about such synthetic reactions with amino acids, except for the report by Hutzinger \& Kosuge (1968), who demonstrated the conversion of indol-3-ylacetic acid into $N^{8}$-(indol-3-ylacetyl)-L-lysine by Pseudomonas savastanoi.

The above results and information suggest that the metabolic reaction demonstrated in this present work is analogous to 'peptide conjugation' known in animals and higher plants. Support for this suggestion is provided by the evidence that the amino acid conjugates accumulated in the culture broth when the concentration of the acid (II) was $0.3 \%$ and, if it was $0.1 \%$ or less, the acid (II) was more rapidly degraded without the apparent accumulation of these conjugates: this means that the conjugates are probably formed by a mechanism similar to the detoxication of foreign compounds in animals (cf. Williams, 1963). Hutzinger \& Kosuge (1968) have also considered that, in the indol-3-ylacetic acid metabolism with $P S$. 
savastanoi, $N^{2}$-(indol-3-ylacetyl)-L-lysine might be formed by the detoxication mechanism. From this point of view, the conjugates (III $a),(\mathrm{III} b),(\mathrm{III} c)$ and (IIId) are probably not the intermediate metabolites involved in the acid (II) degradation by $C$. equi. Thus the present reaction observed with $C$. equi could be considered as 'amino acid conjugation in bacteria'. The present results are also noteworthy from the viewpoint of comparative biochemistry: glutamine is a common reagent for conjugation in man and chimpanzee (cf. Williams, 1963) and also in C. equi, although it is not established yet whether glutamine itself participates in the formation of the glutamine conjugate (IIId) in $C$. equi, as discussed below. Further, it may be noted that in animals a conjugation product is removed from the body, but in C. equi it is further metabolized by this organism, on continued incubation.

'Peptide conjugation' in animal tissues proceeds by the following two mechanisms (cf. Williams, 1963): (1) involves the formation of CoA derivatives of foreign carboxylic acid; (2) an attack by a nucleophilic agent such as glycine on the resulting acyl-CoA derivatives. It is therefore conceivable that the Lalanine and glutamic acid conjugates, compounds (III $a$ ) and (III $b$ ), would be formed by the respective attack by L-alanine and glutamic acid on (4R)-4[4 $\alpha$-(2-carboxyethyl)-3a $\alpha$-hexahydro-7a $\beta$-methyl-5oxoindan-1 $\beta$-yl]valeryl-CoA. However, since amino acids could be acylated with both indol-3-ylacetylCoA and indol-3-ylacetyl-AMP (cf. Shantz, 1966), the possibility that an activated form of the acid (II) comprises both the above CoA derivative and the corresponding hexahydroindanylvaleryl-AMP cannot be excluded. Further, there is also another possibility that a glutamine synthetase-type reaction in bacteria (cf. Stadtman \& Ginsburg, 1974) might participate in this bacterial conjugation. The $O$-acetylhomoserine and glutamine conjugates, compounds (IIIc) and (IIId), are probably formed by either the respective direct conjugation of the acid (II) with $\boldsymbol{O}$-acetylhomoserine and glutamine or by the $\boldsymbol{O}$ acetylation of the homoserine conjugate (IX) and the amidation of the glutamic acid conjugate (III $b$ ) (or both).
The amino acid conjugates isolated in this present work were not our expected metabolites of the acid (II), which would give an insight into the mechanism of further degradation of this acid. However, we have also found that $C$. equi can degrade the acid (II) to (4R) - 4- $[2 \alpha$ - (2 - carboxyethyl) - $3 \beta$ - (3 - carboxypropionyl)-2 $\beta$-methylcyclopent-1 $\beta$-yl]valeric acid (cf. Hayakawa, 1973, pp. 178-180) and 5-methyl-4-oxooctane-1,8-dioic acid (S. Hayakawa \& T. Fujiwara, unpublished work).

We thank the members of the analytical and the physicochemical departments of this laboratory for analytical and optical data. We are also indebted to Miss I. Sawa of The Institute of Medical Science, University of Tokyo, for the gift of a bacterial strain, and to Dr. M. Ebata of this laboratory for running an amino acid analyser and for his valuable criticism.

\section{References}

Armstrong, M. D. (1949) J. Am. Chem. Soc. 71, 3399-3402

Curtis, R. G., Heilbron, I., Jones, E. R. H. \& Woods, G. F. (1953) J. Chem. Soc. 457-464

Hayakawa, S. (1973) Adv. Lipid Res. 11, 143-192

Hayakawa, S., Fujiwara, T. \& Tsuchikawa, H. (1968) Nature (London) 219, 1160-1161

Hayakawa, S., Kanematsu, Y. \& Fujiwara, T. (1969) Biochem. J. 115, 249-256

Hayakawa, S., Kanematsu, Y., Fujiwara, T. \& Kako, H. (1976a) Biochem. J. 154, 577-587

Hayakawa, S., Hashimoto, S. \& Onaka, T. (1976b) Biochem. J. 160, 745-755

Hutzinger, O. \& Kosuge, T. (1968) Biochemistry 7, 601-605

Lapidot, Y., Rappoport, S. \& Wolman, Y. (1967) J. Lipid Res. 8, 142-145

Norman, A. (1955) Ark. Kemi 8, 331-342

Rao, K. R. \& Sober, H. A. (1954) J. Am. Chem. Soc. 76, 1328-1331

Sakami, W. \& Toennies, G. (1942) J. Biol. Chem. 144, 203-217

Sanger, F. (1945) Biochem. J. 39, 507-515

Shantz, E. M. (1966) Annu. Rev. Plant Physiol. 17, 409-438

Sjövall, J. (1964) Methods Biochem. Anal. 12, 97-141

Stadtman, E. R. \& Ginsburg, A. (1974) Enzymes 3rd Ed. 10, 755-807

Williams, R. T. (1963) in Biogenesis of Natural Compounds (Bernfeld, P., ed), pp. 427-474, Pergamon Press, Oxford 